\title{
Effect of the Substrate Movement on the Optical Properties of ZnO Thin Films Deposited by Ultrasonic Spray Pyrolysis
}

\author{
Ebru Gungor and Tayyar Gungor \\ Physics Department, Science and Arts Faculty, Mehmet Akif Ersoy University, 15100 Burdur, Turkey \\ Correspondence should be addressed to Ebru Gungor, egungor@mehmetakif.edu.tr \\ Received 26 October 2011; Revised 4 January 2012; Accepted 5 January 2012 \\ Academic Editor: Ming-Xing Zhang
}

Copyright (C 2012 E. Gungor and T. Gungor. This is an open access article distributed under the Creative Commons Attribution License, which permits unrestricted use, distribution, and reproduction in any medium, provided the original work is properly cited.

\begin{abstract}
Using a modified ultrasonic spray pyrolysis (USP) system, ZnO thin films were deposited on the substrate moved back and forth $(\mathrm{ZO} 1)$ and rotated $(\mathrm{ZO} 3)$ as well as fixed $(\mathrm{ZO} 2)$ in the conventional USP technique. Prepared thin films are pure $\mathrm{ZnO}$ with a preferred crystalline orientation of $\left(\begin{array}{lll}0 & 0 & 2\end{array}\right)$ in the hexagonal wurtzite structure. Diffraction angle shift implies a decrease lattice parameter along $c$-axis and $a$-axis $0.2 \%$ and $0.3 \%$, respectively. Maximum strain has been found for ZO1 which is about $(-)$ $0.17 \%$. These strain values show that presence of compressive strain due to moving substrates as depositing ZnO films. The film deposition process on the rotated quartz substrate is provided to obtain the thinner film. The grain size and root-mean- square value of roughness increase with thickness. Strong UV emission was observed at $\sim 390 \mathrm{~nm}$ assigned to the band gap transition from photoluminescence measurements. Energy shifted about $39 \mathrm{meV}$ for $\mathrm{ZO} 3$ sample with respect to that of ZO2 film deposited in conventional USP system. This behaviour is confirmed with (002) diffraction peak shifting. So, the compressed lattice will provide a wider band gap for these films. $E_{2}$ phonon frequency values have not given a considerable shifting.
\end{abstract}

\section{Introduction}

Zinc oxide is one of the few metal oxides which can be used in numerous technological applications such as photoelectronic devices, information storage, gas sensors, and catalysis [1-4]. Recently, zinc oxide $(\mathrm{ZnO})$ thin film has received more and more attention, because of its less toxic and low cost.

$\mathrm{ZnO}$ thin films can be prepared by using various deposition techniques, such as reactive evaporation [5], RF sputtering [6], chemical vapor deposition (CVD) [7], ultrasonic spray pyrolysis (USP) [8], and sol-gel method [9]. The ultrasonic spray pyrolysis method is one of the preferred method for the deposition of thin films of metallic oxides such as the $\mathrm{ZnO}$ material. In this method, various processing parameters such as substrate temperature, the distance between nozzle and substrate, precursor solution flow rate, spraying geometry, and carrier gas flow rate can be optimized in order to determine how these affected morphology, stoichiometry, crystallography, electrical properties, and optical properties of deposited thin films. When the optimum parameters are obtained, a starting solution, containing $\mathrm{Zn}$ precursor, is sprayed by means of a ultrasonic nozzle, assisted by a carrier gas, over a fixed hot substrate.

The substrate is very important for the growth of thin films in terms of the lattice and thermal mismatching between the film and substrate because the lattice mismatch between the film and the substrate commonly leads to the development of stress in the deposited film. Similarly, thermal mismatch between the film and the substrate contributes to the stress. It is known that the strain affects the conduction bands of $\mathrm{Si}, \mathrm{Ge}$, and direct gap III-V semiconductors differently due to the positions of their band edges in the Brillouin zone [10]. Also, the substrate movement can cause to the growth strain-induced in the films. Because, nucleation and binding of growth species may vary due to the movement of substrate. This affects crystalline quality as well as optical and electrical properties of $\mathrm{ZnO}$ film.

In the literature, some of the modifications made included varying the spraying geometry and movement of the substrate placed on the heater. There are some studies related to the moving substrate placed on the heater for 


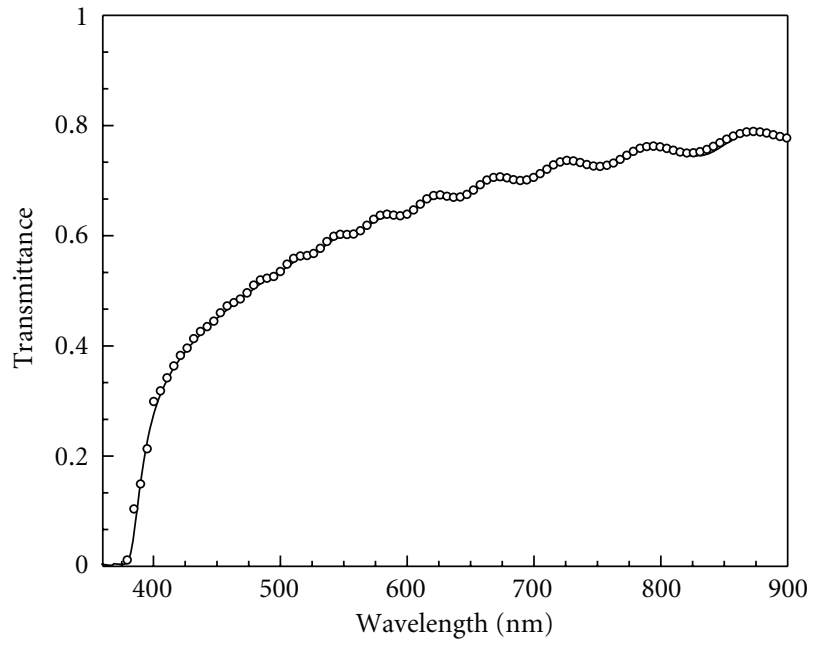

Linear moved - Experimental - Theoretical

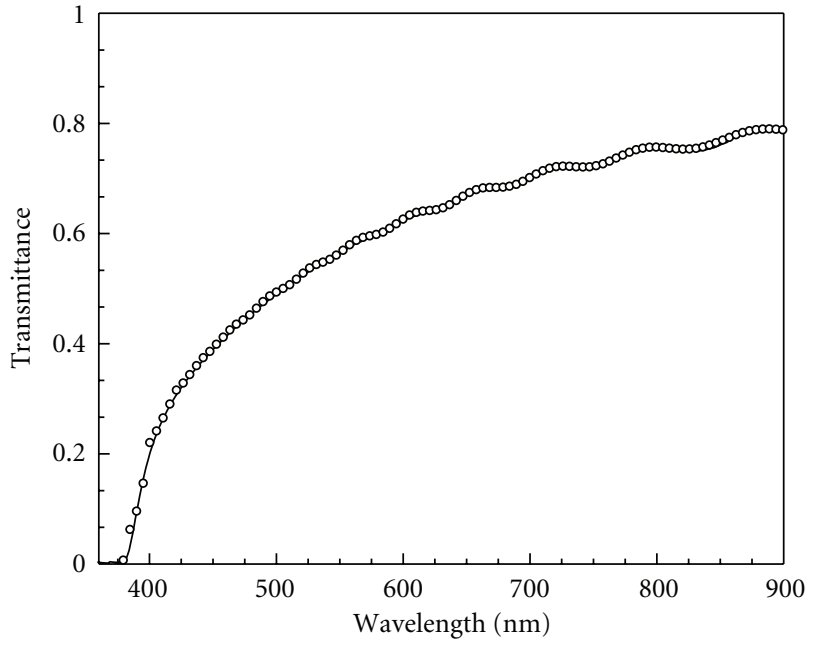

Fixed

- Experimental

- Theoretical

(a)

(b)

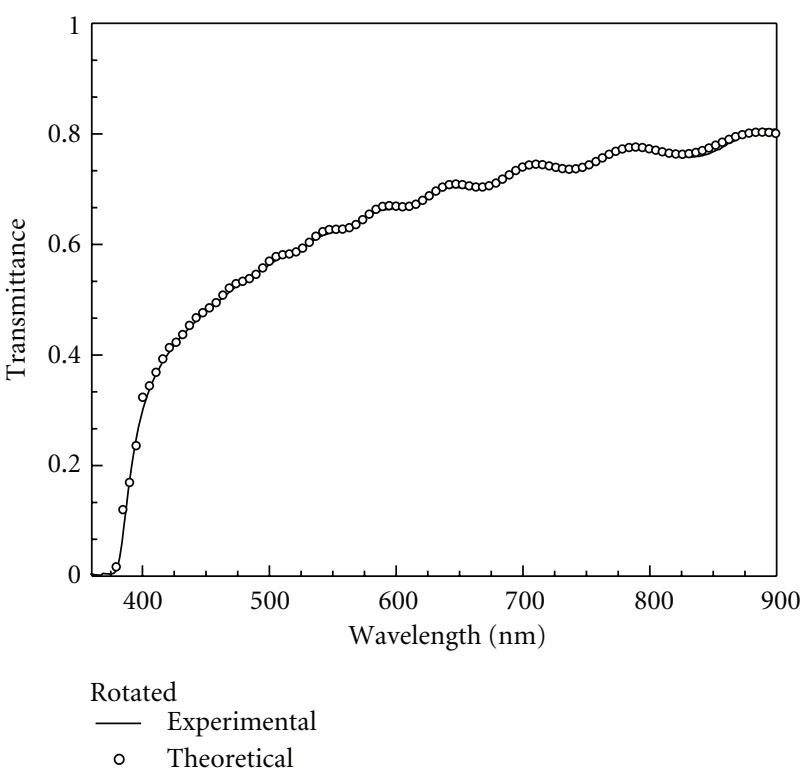

(c)

FiguRe 1: Experimental optical transmission spectra (solid line) of $\mathrm{ZnO}$ thin films: (a) on the linear moved substrate at the horizontal axis, (b) on the fixed substrate, and (c) on the rotated substrate in the horizontal plane. Also the theoretical optical transmission spectra ("o" symbol) are shown for comparison.

$\mathrm{ZnO}$ thin films prepared by the ultrasonic spray pyrolysis systems [11]. However, no studies comparing the effects of substrate motion such as circular and axial movement with respect to fixed substrate have been found. Therefore, in this study, we discussed the substrate motion effect on the structural and optical properties of transparent $\mathrm{ZnO}$ thin films prepared by the ultrasonic spray pyrolysis systems. A number of characterization techniques including X-ray diffraction (XRD), atomic force microscopy (AFM), Raman spectroscopy and photoluminescence (PL), and optical transmission measurements were used to obtain structural and optical properties.

\section{Materials and Methods}

$\mathrm{ZnO}$ thin films were deposited onto ultrasonically cleaned quartz substrates using the spray pyrolysis method at $365^{\circ} \mathrm{C}$. The solution used was $0.1 \mathrm{M}$ zinc acetate $(\mathrm{Zn}(\mathrm{CH} 3 \mathrm{COO})$ 2.2H2O, 99.9\%-Merck) diluted in methanol and deionized 
TABLE 1: Film thickness $t(\mathrm{~nm})$ and comparison of $E_{g}(\mathrm{eV})$ optical band gap values from inflexion point equation and photoluminescence (PL) analysis for $\mathrm{ZnO}$ thin films labelled as $\mathrm{ZO} 1$ for linear moved, $\mathrm{ZO} 2$ for fixed, and $\mathrm{ZO} 3$ for rotated substrate.

\begin{tabular}{lcccrc}
\hline & & Inflexion point equation & \multicolumn{2}{c}{ PL analysis } \\
Sample & $t$ & $E_{g}$ & $\lambda_{1}$ & $E_{g}$ \\
$(\mathrm{~nm})$ & $(\mathrm{eV})$ & 393.08 & 3.157 & $\lambda_{2}$ \\
$(\mathrm{~nm})$
\end{tabular}

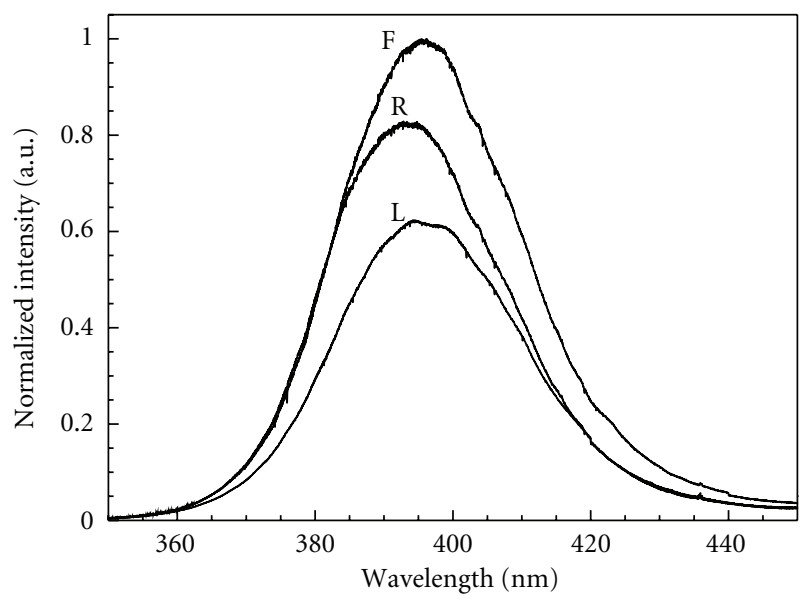

Figure 2: PL spectra of $\mathrm{ZnO}$ thin films at room temperature (The labels $\mathrm{R}, \mathrm{L}$, and $\mathrm{F}$ were used for deposited film on the rotated substrate, for deposited film on the linear moved substrate and for deposited film on the fixed substrate, resp.).

water. The solution flow rate was held constant at $5 \mathrm{~mL} / \mathrm{min}$. The nozzle, $100 \mathrm{kHz}$ oscillator frequency, was at a distance of $12 \mathrm{~cm}$ from the substrate during deposition. Nozzle used in this study was in a downward vertical configuration. Compressed air was used as the carrier gas. The films were deposited for 10 minutes. For conventional USP method, the substrates are fixed and precursor solution sprayed over a hot substrate. $\mathrm{ZnO}$ thin films were deposited for three different cases considered for the movement of the quartz substrate. In the first case, the substrate placed on the heater which $\mathrm{ZnO}$ film was deposited on was moved back and forth (ZO1). In the second case, the substrate placed on the heater was fixed ( $\mathrm{ZO} 2)$, and in the last case the substrate on the heater was rotated (ZO3). Both back and forth (linear motion) and rotational motions were controlled by stepper motor driver unit. The step motor driver unit consists of a decoder and a power unit. D0-D7 data bits obtained from printer port were as the control bits for the driver unit. L297N is used as a decoder. The back, forth, and rotational motions were controlled by using D0-D3 and D4-D7 data bits, respectively. Four BD135 transistors were used to drive the power unit. A linear and angular speeds are $0.25 \mathrm{~cm} / \mathrm{s}$ and $1.25 \mathrm{rpm}$, respectively.

The optical measurements of the $\mathrm{ZnO}$ thin films were carried out at room temperature using Carry-100 Spectrophotometer in the wavelength range $300-900 \mathrm{~nm}$. The structural analysis of the films was performed with a PHILIPS X'PERT PRO series X-Ray automatic diffractometer with $\mathrm{CuK}_{\alpha}(\lambda=1.54056 \AA)$ radiation and scanning angle $2 \theta$ was varied in the range between $20^{\circ}$ and $90^{\circ}$ with a step of $0.03^{\circ}$. AFM Studies were performed on a TopoMetrix TMX 2000 Explorer model atomic force microscope, operating in contact mode in air. Photoluminescence (PL) spectra were measured using a $100 \mathrm{~mW} \mathrm{He}-\mathrm{Cd}$ laser $(\lambda=325 \mathrm{~nm})$ as the excitation source and a HORIBA Jobin-Yvon $1 \mathrm{~m}$ monochromator. Raman spectra were recorded with $532 \mathrm{~nm}$ laser source ( $20 \mathrm{~mW}$, illumination time $20 \mathrm{~s}$ ) Bruker Senterra Raman Spectrometer in the spectroscopic region $300 \mathrm{~cm}^{-1}$ to $1300 \mathrm{~cm}^{-1}$.

\section{Results and Discussion}

The obtained UV-Vis transmission spectra for $\mathrm{ZnO}$ films and the pointwise unconstrained minimization algorithm (PUMA) [12] have been used for computing accurate values of optical constants such as film thickness of $2560 \mathrm{~nm}$, $2435 \mathrm{~nm}$, and $2130 \mathrm{~nm}$ for ZO1, ZO2, and ZO3 samples, respectively (Table 1). PUMA works well not only in the medium and weak absorption region but also in the highabsorption region with or without the interference fringes in the optical transmission spectrum [13]. There are excellent agreement with the experimental spectra and theoretical spectra. The experimental optical transmission spectra are shown in Figures 1(a), 1(b), and 1(c).

It was seen that the transmission values of the films are less than $80 \%$ in the visible region. This situation can be associated with film thicknesses. The results are in compliance with the literature [14]. Despite the same film deposition parameters, the changes in the film thickness can be attributed to the effects of substrate motion.

Optical band gaps of the deposited films were determined from the optical transmission spectra by using the relation,

$$
E_{g}(\mathrm{eV})=\frac{1240.8}{\lambda_{c}(\mathrm{~nm})}
$$

where $\lambda_{c}$ is the critical wavelength defined as the inflexion point of the absorption edge: practically, its position is determined from the second derivative of the transmission curve. This is called as inflexion point method [15]. Calculated $E_{\mathrm{g}}$ values were given in Table 1 .

Figure 2 shows the PL spectra of as-grown samples. Spectra were normalized with regard to the maximum peak value observed for $\mathrm{ZnO}$ film on the fixed substrate 


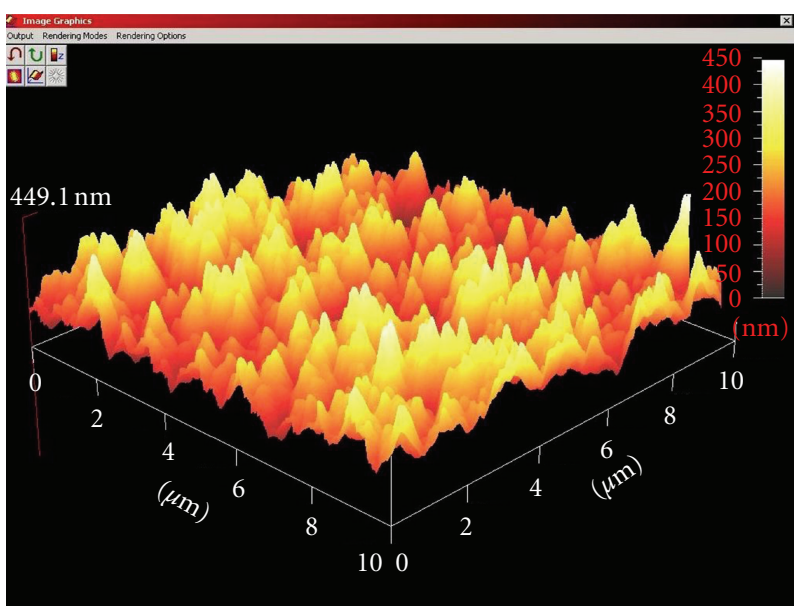

(a)

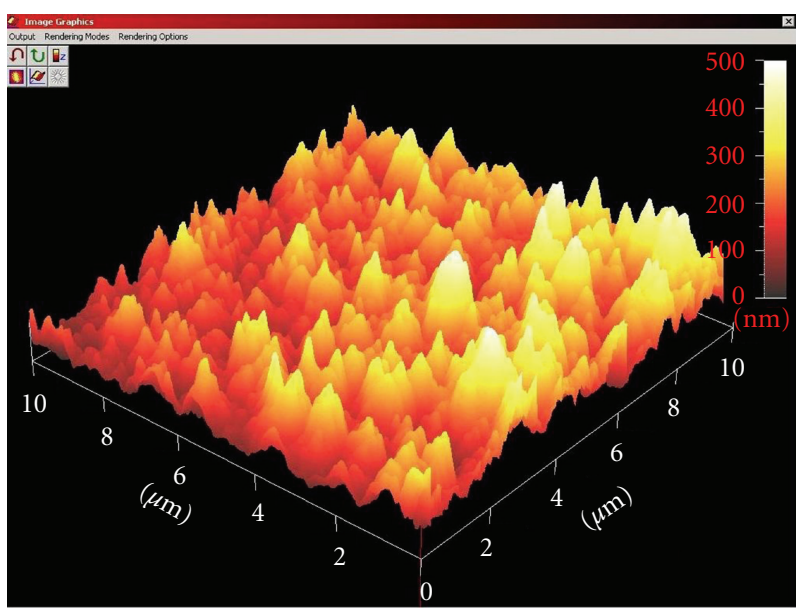

(b)

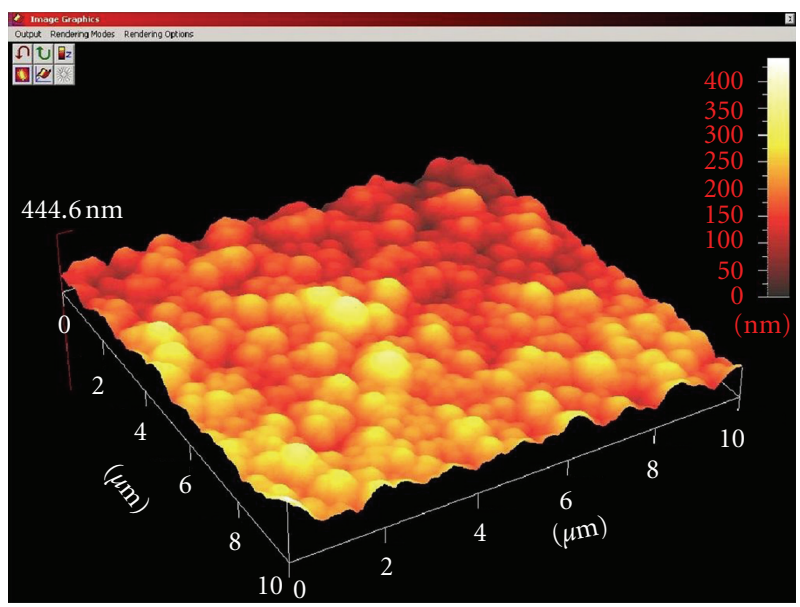

(c)

Figure 3: AFM micrographs of $\mathrm{ZnO}$ thin films: (a) on the linear moved substrate at the horizontal axis, (b) on the fixed substrate, and (c) on the rotated substrate in the horizontal plane.

(ZO2). Photoluminescence spectra of the samples have been recorded at room temperature. The PL emission in the UV bands was observed. Band-edge transitions are observed as well as direct-band transitions. Gaussian fitting was performed on the PL spectra, and two peaks (Table 1) centered around $390 \mathrm{~nm},\left(\lambda_{1}\right)$ was assigned to the band gap transition and $400 \mathrm{~nm},\left(\lambda_{2}\right)$ was assigned to the near-bandedge (NBE) emission were obtained. The strain affects the conduction bands of direct gap semiconductors due to the positions of their band edges in the Brillouin zone [10]. From the PL spectra, UV emission peak shifts to $3.195 \mathrm{eV}$ for the film on the rotated substrate (ZO3). It is observed that energy shifted about $39 \mathrm{meV}$ for $\mathrm{ZO} 3$ sample with respect to that of ZO2 film deposited in conventional USP system. This case can be consistent with the compressive strain effect on the electronic band structure if coupling from the other bands is neglected. If strain shifts the other bands, the energy distance between them and the conduction band will change.

In Figures 3(a), 3(b), and 3(c), it was observed that the topology of the films surface is affected by substrate motion.
From the AFM results, the particles are packed closely and well distributed on the substrate and the minimum root mean square (rms) surface roughness is $36 \mathrm{~nm}$ and clearly spherical morphology has been observed in case of the rotated substrate (ZO3). However, the rms surface roughness is $50 \mathrm{~nm}$ and $41 \mathrm{~nm}$ when the substrate moved back and forth (ZO1) and the substrate remained fixed ( $\mathrm{ZO} 2)$, respectively. The films deposited on quartz substrates are physically stable and have good adhesion to the substrate. The chipping or delaminating was not observed.

The effect of substrate movement on the structural characteristics of $\mathrm{ZnO}$ films is shown in Figures 4(a), 4(b), and $4(\mathrm{c})$. The X-ray diffractograms show that all of the obtained films were polycrystalline with a hexagonal wurtzite structure, and only the (002) peak of $\mathrm{ZnO}$ indicates a strong orientation along the $c$ axis. On the other hand, the diffractograms show also the presence of (100), (002), (101), (102), (110), (103), (112), and (004) peaks indicating a random orientation of the hexagonal crystallites in the polycrystalline films. The substrate motion affects the peak 


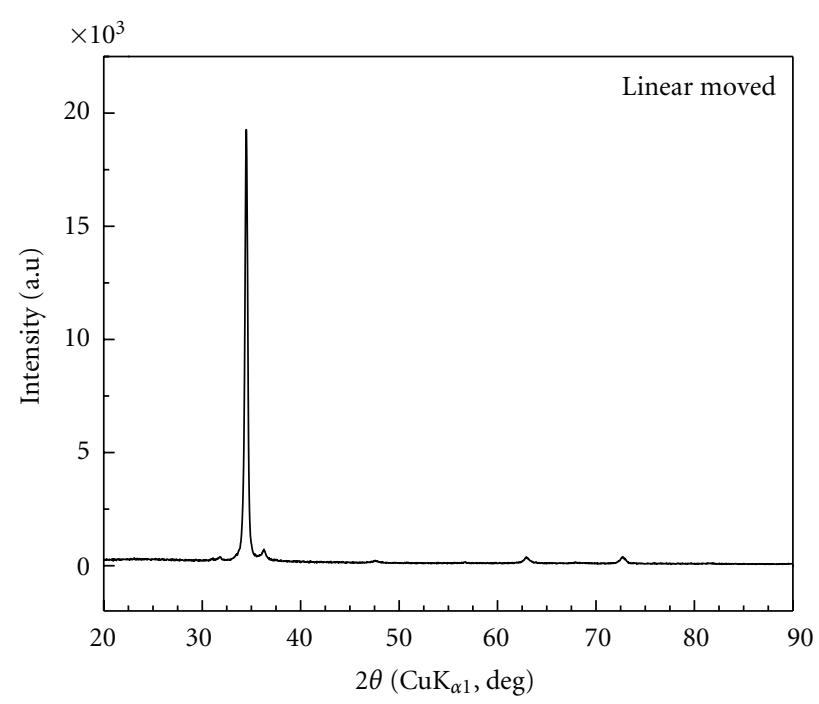

(a)

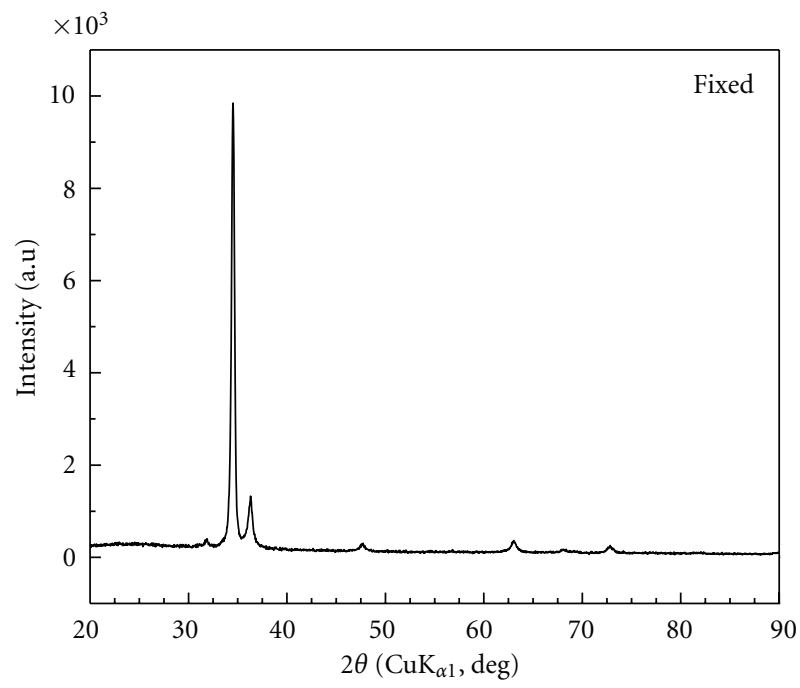

(b)

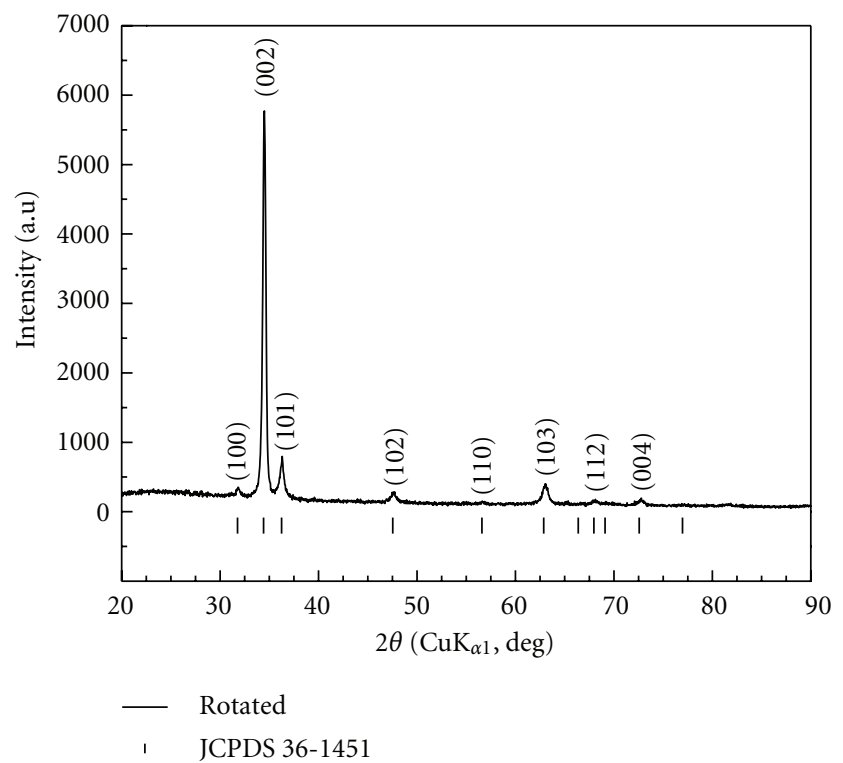

(c)

Figure 4: X-ray diffraction patterns of $\mathrm{ZnO}$ thin films, (a) on the linear moved substrate at the horizontal axis, (b) on the fixed substrate, and (c) on the rotated substrate in the horizontal plane, and "|" symbol indicates the reference (JCPDS 36-1451).

intensities (Figure 5). The highest intensity for (002) peak was observed for ZO1 sample, the lowest peak intensity was observed for $\mathrm{ZO} 3$ sample. The decrease of peak intensity is correlated with the decrease of the film thickness.

The average crystalline size of the $\mathrm{ZnO}$ film was estimated from X-ray diffraction using Scherrer formula [16],

$$
D=\kappa \frac{\lambda}{\beta \cos \theta},
$$

where $\beta$ is the full width of the half-maximum (FWHM) of the peak corrected for instrumental broadening, $\lambda$ is the wavelength of the $\mathrm{X}$-ray, $\theta$ is the Bragg diffraction angle, and $\kappa(0.94)$ is Scherrer's constant. The values found for the grain size at three different samples are about $34 \mathrm{~nm}$.
It is found that diffraction angles of (002) and (100) peaks of all samples, as shown in Figure 5, are larger than $34.42^{\circ}$ and $31.77^{\circ}$ of $\mathrm{ZnO}$ taken from the JCPDS 361451, respectively. This angular shift implies a decreased lattice parameter along $c$-axis and $a$-axis $0.2 \%$ and $0.3 \%$, respectively. This indicates a stress along both directions. The calculated lattice parameters, out-of-plane strains, have been summarized in Table 2. The out-of-plane strain along the $c$ axis, $\varepsilon_{z z}$, is given by the following equation:

$$
\mathcal{E}_{z z}(\%)=\frac{c-c_{0}}{c_{0}},
$$

where $c$ is the lattice parameter of the strained $\mathrm{ZnO}$ films calculated from X-ray diffraction data and $c_{0}$ is the 
TABle 2: Structural parameters of ZnO thin films labelled as ZO1 for linear moved, ZO2 for fixed, and ZO3 for rotated substrate; XRD results; diffraction angle $2 \theta$ and FWHM for (002) peak, crystallinite size $D$, lattice parameters, and strain along $c$-axis $\varepsilon_{z z}$ and Raman results; $E_{2}$ phonon mode.

\begin{tabular}{lccccccc}
\hline Sample & $\begin{array}{c}2 \theta \\
(\text { degree })\end{array}$ & $\begin{array}{c}\text { FWHM } \\
(\text { degree })\end{array}$ & $\begin{array}{c}D \\
(\mathrm{~nm})\end{array}$ & $\begin{array}{c}c \\
(\AA)\end{array}$ & $\begin{array}{c}a \\
(\AA)\end{array}$ & $\begin{array}{c}\mathcal{E}_{z z} \\
(\%)\end{array}$ \\
\hline ZO1 & 34.483 & 0.23539 & 36.91 & 5.19772 & 3.24612 & -0.171 \\
ZO2 & 34.524 & 0.26269 & 33.08 & 5.19158 & 3.24006 & -0.289 \\
ZO3 & 34.494 & 0.26623 & 32.63 & 5.19596 & 3.24393 & -0.204 & 439.73 \\
\hline
\end{tabular}

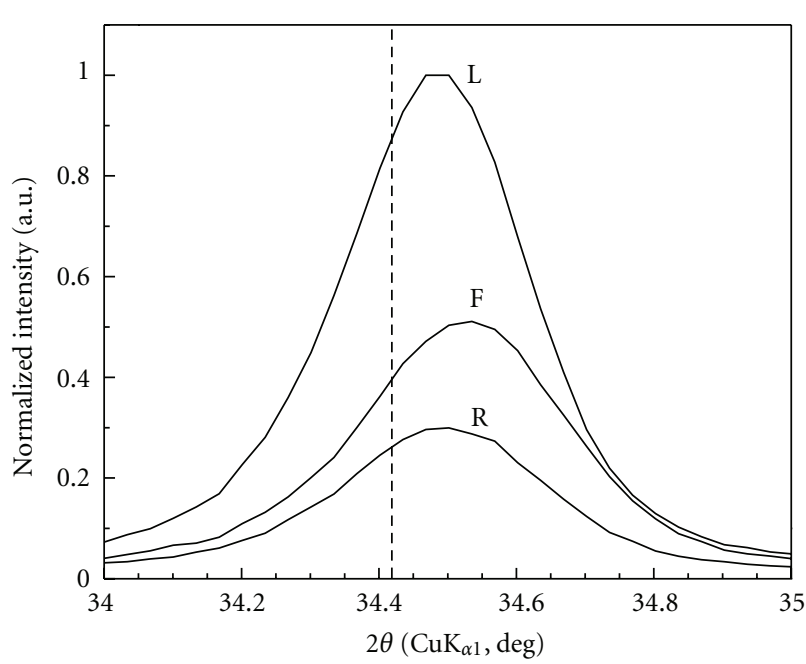

Figure 5: Diffraction angle shift of (002) peak for the $\mathrm{ZnO}$ thin films. Peak intensities are normalized with respect to that of $\mathrm{ZnO}$ film on the linear moved substrate (Label L, F, and R show the deposited films on the linear moved substrate, on the fixed substrate, and on the rotated substrate, resp.). Dashed line indicates reference value $\left(34.42^{\circ}\right)$.

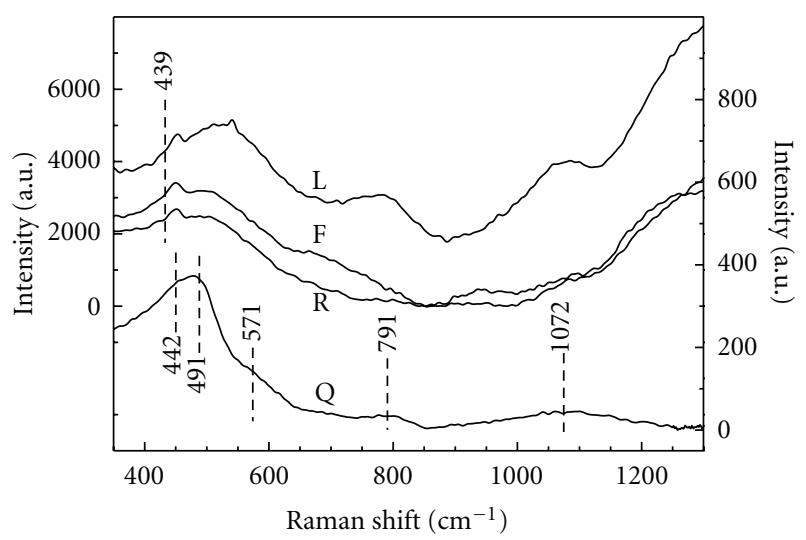

Figure 6: Raman spectra of ZnO thin films (Label L, F, R, and Q show the films on the linear moved substrate, on the fixed substrate, on the rotated substrate, and quartz substrate, resp.).

unstrained lattice parameter of $\mathrm{ZnO}$ [10]. The minimum strain value has been found for $\mathrm{ZnO}$ film on fixed substrate ( $\mathrm{ZO} 2$ ) which is about $(-) 0.29 \%$, and maximum strain has been found for $\mathrm{ZnO}$ film on the linear moved substrate (ZO1) which is about $(-) 0.17 \%$. The strain values show that presence of compressive strain in $\mathrm{ZnO}$ films. So, the lattice will compressed due to moving substrates as depositing $\mathrm{ZnO}$ films, and the compressed lattice will provide a wider band gap for these films. Band gap is altered by the strain as a result of strain-shifted conduction and valence band edges. It can be seen that the band gap change under compression is small for $\mathrm{ZnO}$ films on the linear moved and rotated substrates respect to $\mathrm{ZnO}$ film on the fixed substrate.

$\mathrm{ZnO}$ has a hexagonal wurtzite structure and belongs to the $C_{6 v}^{4}\left(\mathrm{P}_{3} m c\right)$ space group. The group theory predicts two $A_{1}$, two $E_{1}$, two $E_{2}$, and two $B_{1}$ modes. Among them, one $A_{1}$, one $E_{1}$, and two $E_{2}$ modes are Raman active [17]. Figure 6 shows the Raman spectra of $\mathrm{ZnO}$ samples. Multi Gaussian peak fitting was performed for Raman spectra of both sample and quartz substrate. While comparing all spectra of $\mathrm{ZnO}$, the several peaks around $442 \mathrm{~cm}^{-1}$, $491 \mathrm{~cm}^{-1}, 571 \mathrm{~cm}^{-1}, 791 \mathrm{~cm}^{-1}$, and $1072 \mathrm{~cm}^{-1}$ belong to quartz substrate modes. The broad peak centered $444 \mathrm{~cm}^{-1}$ involves the overlapped $439 \mathrm{~cm}^{-1}$ and $451 \mathrm{~cm}^{-1}$. The first of the overlapped peaks can be associated with the $E_{2}$ (high) mode of $\mathrm{ZnO}$ and $439.73 \mathrm{~cm}^{-1}, 439.39 \mathrm{~cm}^{-1}$, and $439.44 \mathrm{~cm}^{-1}$ for the linear moved substrate, fixed substrate, and rotated substrate, respectively (Table 2 ). Stress induced in the wurtzite structure affects the $E_{2}$ phonon frequency. An increase in the $E_{2}$ phonon frequency is ascribed to compressive stress, whereas a decrease in the $E_{2}$ phonon frequency is ascribed to tensile stress. Therefore, Raman spectroscopy of the $E_{2}$ phonon mode is a method to evaluate residual stress within $\mathrm{ZnO}$ crystallized films [18]. However, the frequency shift in these samples can not observe a display of compressive stress.

\section{Conclusion}

$\mathrm{ZnO}$ thin films with a hexagonal wurtzite-type structure were successfully produced by the modified ultrasonic spray pyrolysis deposition system. The movement of the substrate placed on the heater was achieved in two ways differed from the conventional USP technique: back and forth linearly and rotational movements. It was observed that there are some minor changes in XRD results and in the optical transmission spectra such as diffraction angle shifting and strength of interference fringes with their corresponding wavelength due to the substrate movement, respectively. XRD is often used to measure the stress of film because strain can be calculated directly by Bragg's equation by measurement of diffraction peak position shift compared to bulk $\mathrm{ZnO}$. At the 
same time, it is also a nondestructive measurement method. Measurement of diffraction peak position shifting implies a decrease lattice parameter along $c$-axis and $a$-axis $0.2 \%$ and $0.3 \%$, respectively. Maximum strain has been found for $\mathrm{ZO} 1$ about $(-) \quad 0.17 \%$ and minimum strain value has also been found for $\mathrm{ZnO}$ film on fixed substrate (ZO2) about (-) $0.29 \%$. AFM micrographs show that the minimum $r m s$ surface roughness $(36 \mathrm{~nm}$ ) and clearly spherical morphology have been observed in the $\mathrm{ZnO}$ film deposited on the rotated substrate $(\mathrm{ZO} 3)$. The grain size and root-mean-square value of roughness increase with thickness. From the PL spectra, strong UV emission was observed at $\sim 390 \mathrm{~nm}(3.195 \mathrm{eV})$ assigned to the band gap transition for the film on the rotated substrate (ZO3). The energy shifted about $39 \mathrm{meV}$ for $\mathrm{ZO} 3$ sample with respect to that of $\mathrm{ZO} 2$ film deposited in conventional USP system. The energy band gap changes in the case of presence of the compressive strain in structure. (002) diffraction peak shifting supports the increase of band gap. This can not be seen clearly in Raman measurements. Considering the experimental results, the substrate should be rotated to obtain uniform thin film and low-surface roughness for $\mathrm{ZnO}$ thin films deposited by USP system.

\section{Acknowledgments}

This study was supported by The Scientific Research Unit of Mehmet Akif Ersoy University with project number 11010 and The Scientific and Technological Research Council of Turkey with project number 105T003. We want to thank Dr. Engin Tiras, Tulay Tiras from Eskisehir Anadolu University, Dr. Suat PAT from Eskisehir Osmangazi University, and Dr. Edip BAYRAM from Akdeniz University.

\section{References}

[1] A. A. El-Fadl, G. A. Mohamad, A. B. A. El-Moiz, and M. Rashad, "Optical constants of $\mathrm{Zn}_{1-x} \mathrm{Li}_{x} \mathrm{O}$ films prepared by chemical bath deposition technique," Physica B, vol. 366, no. 1-4, pp. 44-54, 2005.

[2] S. Faÿ, U. Kroll, C. Bucher, E. Vallat-Sauvain, and A. Shah, "Low pressure chemical vapour deposition of $\mathrm{ZnO}$ layers for thin-film solar cells: temperature-induced morphological changes," Solar Energy Materials and Solar Cells, vol. 86, no. 3, pp. 385-397, 2005.

[3] Y. Du, M. S. Zhang, J. Hong, Y. Shen, Q. Chen, and Z. Yin, "Structural and optical properties of nanophase zinc oxide," Applied Physics A, vol. 76, no. 2, pp. 171-176, 2003.

[4] W. Cun, Z. Jincai, W. Xinming et al., "Preparation, characterization and photocatalytic activity of nano-sized $\mathrm{ZnO} / \mathrm{SnO}_{2}$ coupled photocatalysts," Applied Catalysis B, vol. 39, no. 3, pp. 269-279, 2002.

[5] M. Jin and L. S. Ying, "Preparation of $\mathrm{ZnO}$ films by reactive evaporation," Thin Solid Films, vol. 237, no. 1-2, pp. 16-18, 1994.

[6] A. F. Aktaruzzaman, G. L. Sharma, and L. K. Malhotra, "Electrical, optical and annealing characteristics of $\mathrm{ZnO}$ :Al films prepared by spray pyrolysis," Thin Solid Films, vol. 198, no. 1-2, pp. 67-74, 1991.

[7] M. Purica, E. Budianu, E. Rusu, M. Danila, and R. Gavrila, "Optical and structural investigation of $\mathrm{ZnO}$ thin films prepared by chemical vapor deposition (CVD)," Thin Solid Films, vol. 403-404, pp. 485-488, 2002.

[8] T. Yildirim, E. Gür, S. Tüzemen et al., "Wide-bandgap modification of polycrystalline $\mathrm{ZnO}$ using Sn component on the basis of developing quantum-well hetero-structure," Physica E, vol. 27, no. 1-2, pp. 290-295, 2005.

[9] J. H. Lee and B. O. Park, "Transparent conducting ZnO:Al, In and Sn thin filmsdeposited by the sol-gel method," Thin Solid Films, vol. 426, no. 1-2, pp. 94-99, 2003.

[10] Y. Sun, S. E. Thompson, and T. Nishida, Strain Effect in Semiconductors: Theory and Device Applications, Springer, New York, NY, USA, 2010.

[11] M. Quintana, E. Ricra, J. Rodríguez, and W. Estrada, "Spray pyrolysis deposited zinc oxide films for photo-electrocatalytic degradation of methyl orange: influence of the $\mathrm{pH}$," Catalysis Today, vol. 76, no. 2-4, pp. 141-148, 2002.

[12] E. G. Birgin, I. Chambouleyron, and J. M. Martínez, "Estimation of the optical constants and the thickness of thin films using unconstrained optimization," Journal of Computational Physics, vol. 151, no. 2, pp. 862-880, 1999.

[13] N. Erarslan and T. Gungor, "The determination of the thickness and optical constants of the $\mathrm{ZnO}$ crystalline thin film by using pointwise unconstrained minimization algorithm," The Journal of Graduate School of Natural Applied Science of Mehmet Akif Ersoy University, vol. 1, no. 2, pp. 181-193, 2010.

[14] T. Prasada Rao and M. C. Santhoshkumar, "Effect of thickness on structural, optical and electrical properties of nanostructured $\mathrm{ZnO}$ thin films by spray pyrolysis," Applied Surface Science, vol. 255, no. 8, pp. 4579-4584, 2009.

[15] R. Dolbec, M. A. El Khakani, A. M. Serventi, M. Trudeau, and R. G. Saint-Jacques, "Microstructure and physical properties of nanostructured tin oxide thin films grown by means of pulsed laser deposition," Thin Solid Films, vol. 419, no. 1-2, pp. 230-236, 2002.

[16] B. D. Cullity, The Elements of X-Ray Diffraction, AddisonWesley, Reading, Mass, USA, 2nd edition, 1978.

[17] Ü. Özgür, Y. I. Alivov, C. Liu et al., "A comprehensive review of $\mathrm{ZnO}$ materials and devices," Journal of Applied Physics, vol. 98, no. 4, Article ID 041301, 103 pages, 2005.

[18] S. B. Yahia, L. Znaidi, A. Kanaev, and J. P. Petitet, "Raman study of oriented $\mathrm{ZnO}$ thin films deposited by sol-gel method," Spectrochimica Acta-Part A, vol. 71, no. 4, pp. 12341238, 2008. 

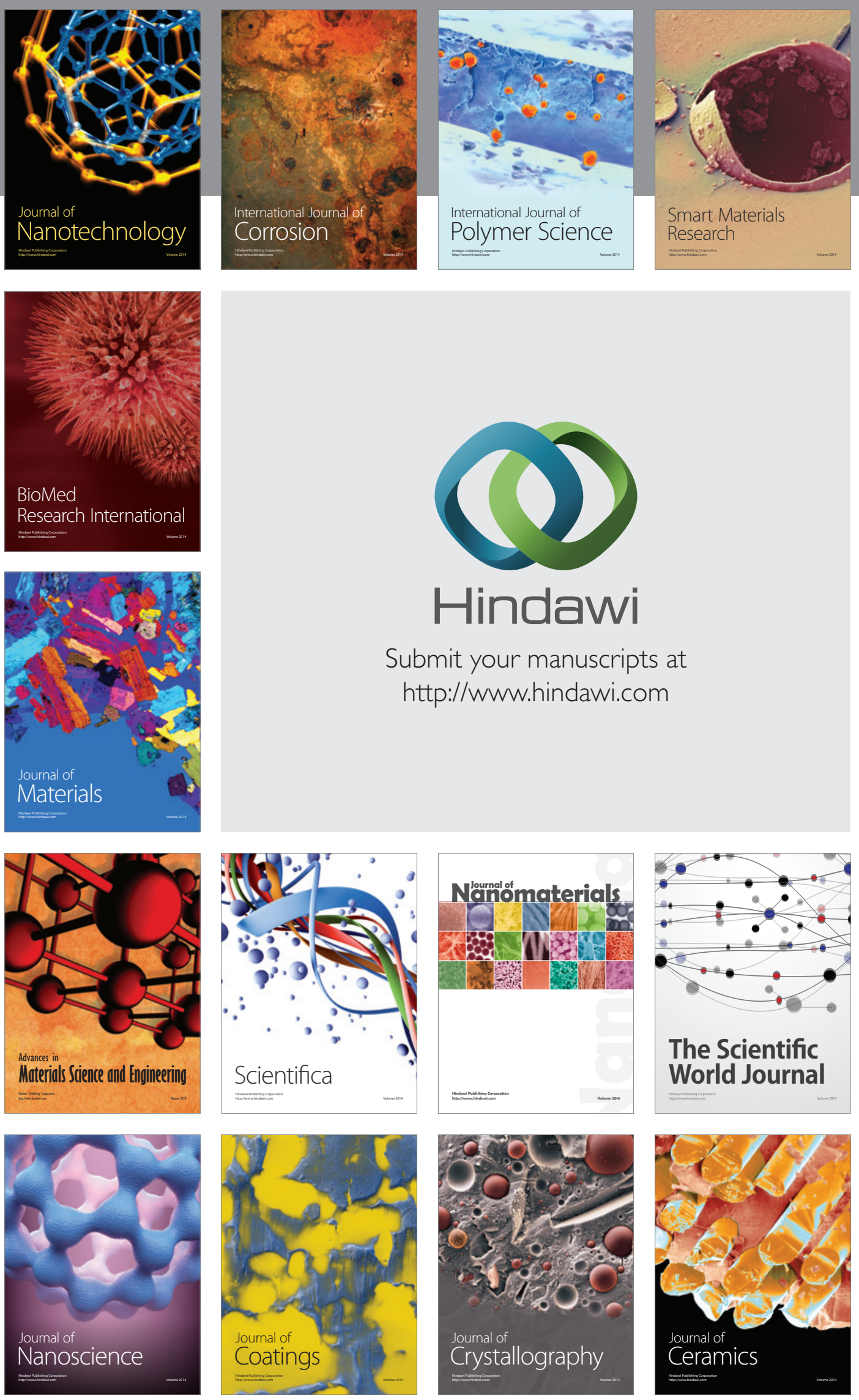

The Scientific World Journal

Submit your manuscripts at

http://www.hindawi.com

\section{World Journal}

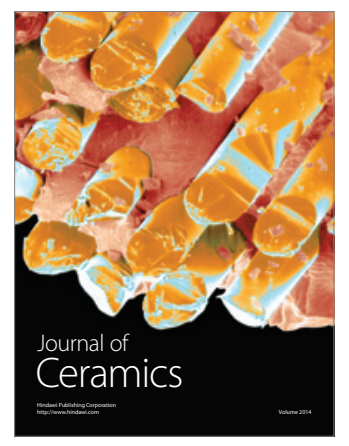

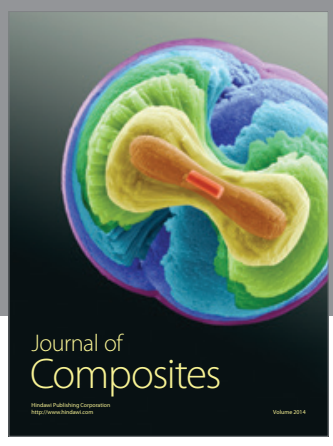
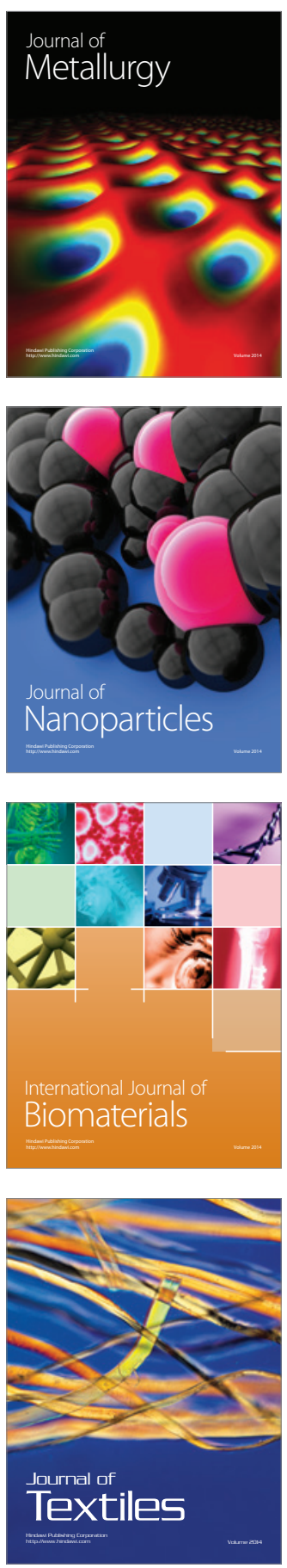